\title{
EL ENRIQUECIMIENTO DEL DONATARIO Y EL EMPOBRECIMIENTO DEL DONANTE*
}

[The Donee's Enrichment and the Donor's Impoverishment]

\author{
Francisca Leitao Álvarez-SalamancA** \\ Universidad de los Andes, Santiago de Chile
}

\begin{abstract}
RESUMEN
Para configurar el concepto de donación entre vivos, la legislación chilena requiere el enriquecimiento del donatario y el empobrecimiento del donante. El trabajo se propone indagar, por una parte, cómo han sido tratados estos requisitos por la doctrina chilena y compararla con la regulación en algunos Códigos Civiles europeos, como el francés, el italiano, el alemán, el austríaco y el español; y, por otra, dilucidar el concepto clásico de la donación romana non mortis causa y entre personas extrañas. En la que hay autores
\end{abstract}

\begin{abstract}
For the donation inter vivos concept to be constituted, the Chilean legislation requires the donee's enrichment and the donor's impoverishment. On one hand, this work intends to explore how these requirements have been handled by the Chilean doctrine and compare them with the regulations in some European Civil Codes, such as the French, the Italian, the German, the Austrian and the Spanish Civil Codes; on the other hand, it aims at elucidating the Roman classic concept of Donation non mortis causa
\end{abstract}

ReCibIDo el 17 de diciembre de 2013 y aCEPTADo el 21 de junio de 2014

* Este trabajo es una adaptación del capítulo séptimo de la tesis doctoral "Una revisión histórico-dogmática de las fuentes concernientes a la fijación del concepto romano-clásico de 'donación no por causa de muerte" defendida por la autora el 10 de enero de 2012. Él, además, forma parte del Proyecto Anillo-CONICYT, código SOC 1111.

** Profesora de derecho romano en la Universidad de los Andes. Dirección postal: Universidad de los Andes, Facultad de Derecho, Monseñor Álvaro del Portillo ${ }^{\circ}$ 12.455, Las Condes, Santiago, Chile. Correo electrónico: franciscaleitao@uandes.cl. 
que exigen por un lado, el enriquecimiento (locupletatio) del donante y el empobrecimiento del donatario (pauperimento) por otro. Y otros que de producirse dichos elementos, afirman que estaríamos frente a las donaciones entre cónyuges, las cuales están prohibidas.

\section{Palabras clave}

Donación - Enriquecimiento -Empobrecimiento. and between strangers. Wherein there are authors that require, on one hand, the donor's enrichment (locupletatio) and the donee's impoverishment (pauperimento), on the other. In addition, there are others that affirm that, if those circumstances take place, we would be facing a donation between spouses, which are prohibited.

KeYWORDS

Donation - Enrichment -Impoverishment.

\section{LOS REQUISITOS DEL ENRIQUECIMIENTO Y EMPOBRECIMIENTO EN LA LEGISLACIÓN}

En esta primera parte del trabajo indagaremos los requisitos del enriquecimiento del donatario y el empobrecimiento del donante en la legislación chilena y en algunas extrajeras que nos han parecido más relevantes.

\section{El enriquecimiento y empobrecimiento en el "Código Civil" de Chile.}

El artículo $1398 \mathrm{CCCh}$. dice: "No hay donación, si habiendo por una parte disminución de patrimonio, no haypor otra aumento; como cuando para un objeto que consume el importe de la cosa donada, y de que el donatario no reporte ninguna ventaja apreciable en dinero". La doctrina chilena -que no es abundante en esta materia- ha entendido que para la existencia de una donación entre vivos se requieren dos elementos: por un lado un enriquecimiento en el patrimonio del donatario, y por otra, un empobrecimiento en el del donante ${ }^{1}$. Sin perjuicio de lo anterior, Guzmán acerca de la misma norma

${ }^{1}$ Véase: Abeliuk, René, Derecho sucesorio ( $8^{a}$ edición, Santiago de Chile, Editorial Jurídica de Chile, 2012), II, pp. 702-704: expresa: “[...] la donación, además de los requisitos comunes a todo contrato estudiados, tiene una exigencia, que le es propia y característica. Para que exista donación es necesario que haya un empobrecimiento del patrimonio del donante y un enriquecimiento del acervo del donatario. [...]"; Lecaros Sánchez, José Miguel, Liberalidades y donaciones irrevocables (Santiago, Metropolitana Ediciones, 1997), p. 57, textualmente expresa: "De modo tal que para que haya donación es necesario un empobrecimiento de un patrimonio, un enriquecimiento de otro patrimonio, y un vínculo de causalidad entre el empobrecimiento y el enriquecimiento". Lo anterior lo fundamenta con jurisprudencia al respecto. Así por ejemplo, cita el siguiente caso (recogido del Revista de Derecho y Jurisprudencia, 26, sec., 
expresa: “[...] Mas, propiamente [la norma[ no niega que haya donación si no existe disminución en el patrimonio del donante, disminución que, por consiguiente, no exige. [...]” ${ }^{2}$. Añade que la redacción del artículo 1398 es ambigua, por lo que la interpretación de la norma y por los ejemplos que después se citan en el mismo Código, obedecen a que se necesite "[...] un cambio correlativo en ambos patrimonios; vale decir, una disminución en el del donante y un aumento en el del donatario. [...]"3. Además es necesario advertir que el Código no se expresa exactamente con los términos "empobrecimiento" y "enriquecimiento", sino que utiliza los vocablos "disminución" de patrimonio y "aumento" del mismo. La utilización de esta terminología obedece a que la formulación de este dogma viene del Derecho romano, que, como veremos más adelante, sólo exigía el enriquecimiento del donatario y el empobrecimiento del donante para verificar si existía o no una donación entre cónyuges ${ }^{4}$.

\section{El enriquecimiento y empobrecimiento en algunos Códigos civiles europeos.}

Resulta relevante indagar si otros códigos civiles europeos también exigen empobrecimiento y enriquecimiento.

El Código Civil francés regula la materia en su libro III, título $2^{\circ}$ : "Des donations entre-vifs et des testamens". De la lectura de todo el título y buscando si éste exige o no el requisito a la donación concluimos que no. Es así como define a la donación en su artículo 894 como: "La donation entre-vifs es un acte par lequel le donateur se dépouille actuellement et irrévocablement de la chose donnée, en faveur du donataire qui l'accepte". Podría sostenerse que, por el hecho que el donante deba despojarse ("dépouiller") de la cosa donada, se implica que deba existir una disminución de su patrimonio; pero el hecho es que el Code no lo exige de manera explícita.

En la misma línea del Code se encuentra el Allgemeines Bürgerliches Gesetzbuch austríaco En él, la donación va regulada en la parte rubricada:

$2^{\text {a }}$, p. 38) de un "seguro de vida, lo que el cónyuge recibe de la compañía no es a título de donación hecha por el cónyuge difunto pues no cabe sostener que haya relación de causalidad entre el pago del seguro que significa un enriquecimiento para el cónyuge sobreviviente y un empobrecimiento del cónyuge difunto. Ello dado que el valor del seguro no le pertenecía al pre-muerto", p. 61; Kiverstein, Abraham, Sucesión por causa de muerte y donaciones entre vivos ( $4^{a}$ edición, Santiago, La Ley, 2000), p. 363; MEZA BARros, Ramón, Manual de la sucesión por causa de muerte y donaciones entre vivos ( $8^{\mathrm{a}}$ edición, Santiago de Chile, Editorial Jurídica de Chile, 2007), p. 208. Desarrolla en forma breve la norma del artículo 1398.

${ }^{2}$ GuZmán Brito, Alejandro, De las donaciones entre vivos, conceptos y tipos (Santiago de Chile, LexisNexis, 2005), p. 53.

${ }^{3}$ Ibíd., p. 54.

${ }^{4}$ Ibíd., véase la historia del dogma, esto es el origen del requisito, pp. 54-59. 
"Von den persönlichen Sachenrechten", entre los parágrafos 938 al 956. $\mathrm{Su}$ estudio no muestra ninguna norma que establezca como requisito de la donación el enriquecimiento del donatario y el empobrecimiento del donante, lo cual ni siquiera aparecer insinuado en la definición que ofrece el $\$ 938$ "Ein Vertrag, wodurch eine Sachejemandem unentgeltlich überlassen wird, heißt eine Schenkung".

El Código Civil español, siguiendo al francés, sitúa la donación en el libro III: "De los diferentes modos de adquirir". En su título $2^{\circ}$, después de haber tratado la ocupación, la define en el artículo 618: "La donación es un acto de liberalidad por el cual una persona dispone gratuitamente de una cosa en favor de otra, que la acepta". Sin embargo, el artículo 621 indica que las donaciones entre vivos se rigen según las normas de los contratos y obligaciones. Podemos concluir que el Código hispano no exige para que haya donación el enriquecimiento del donatario y el empobrecimiento del donante.

A diferencia de los códigos antes expuestos se encuentra el Bürgerliches Gesetzbuch alemán. Trata de la donación en su libro II: "Recht der Schuldverhältnisse" ("Derecho de las relaciones obligatorias"), en la sección 7a: "Einzelne Schuldverhältnissegern" ("Relaciones obligacionaleds singulares") título $2^{\circ}$. Ya en la definición, contenida en el $\$ 516$, establece que la donación es: "Eine Zuwendung, durch diejemand aus seinem Vermögen einen anderen bereichert, ist Schenkung, wenn beide Teile darüber einig sind, dass die Zuwendung unentgeltlich erfolgt" "Una atribución por la cual alguien enriquece a otro con su patrimonio es donación si ambas partes han convenido en que la atribución tiene lugar gratuitamente"). Según ella, se entiende que hay donación cuando una persona confiere a otra en propiedad una cosa que la enriquece ("bereichern") a costa de su propio patrimonio en forma gratuita. Pero en el resto del título que regula la donación no encontramos formulado el requisito del empobrecimiento del donante y como dijimos, sólo en la definición se hace alusión al enriquecimiento que también puede ser entendido como un beneficio del donante al donatario.

El Codice Civile italiano define la donación en su artículo 769, que expresa: "La donazione è il contratto col quale, per spirito di liberalità, una parte arricchisce l'altra, disponendo a favore di questa di un suo diritto o assumendo verso la stessa una obbligazione". Esta norma se encuentra situada en el título $5^{\circ}$ : "Delle donazioni" de su libro II: "Delle successioni". De la misma manera a como lo hace el BGB., aquí, ya en el concepto mismo de la donación, se exige el enriquecimiento del donatario ("una parte arricchisce l'altra"). Sin embargo, nada dice acerca de la disminución patrimonial del donante como requisito de la donación.

De todo lo anterior podemos afirmar que el Código Civil de Chile sale de la órbita de todos los códigos citados, en cuanto a que ninguno exige el 
empobrecimiento del donante, y que sólo algunos, como el BGB y el Código Civil italiano establecen el enriquecimiento del donatario.

\section{EL ENRIQUECIMIENTO Y EMPOBRECIMIENTO EN LA ROMANÍSTICA Y EN SUS FUENTES}

Es necesario indagar si los juristas romanos de la época clásica exigían, para configurar su concepto de donación, el enriquecimiento (locupletatio) del donante y el empobrecimiento del donatario (depauperatio).

$\mathrm{Al}$ respecto observamos dos posturas: por un lado, algunos autores unen ambos componentes tratándolos como un todo unitario, lo que les ayuda conformar la misma donación o la causa donandi. Por otro lado, la doctrina mayoritaria los trata en forma separada e incluso algunos autores acotan muchísimo más la exigencia sólo para el caso de las donaciones entre marido y mujer, entendidas en el contexto del matrimonio sine manus. Esto es, si uno de los cónyuges se hace más rico a costa del otro, o se empobrece se configura una donación y por tanto estaría prohibida.

\section{Estado de la cuestión.}

a) "Locupletatio-depauperatio" en Savigny. La postura de Savigny se encuentra recogida en su System des heutigen römischen Rechts. Aquel autor da a entender que una donación sólo existe en el evento en que una de las partes sufra una disminución cuantitativa en su patrimonio (depauperatio) y la otra lo vea aumentado (locupletatio) $)^{5}$, lo cual significa que una

${ }^{5}$ Cfr., Savigny, F. K., Sistema del derecho romano actual (trad. cast., por Jacinto Mesía y Manuel Poley, Madrid, Editorial de Góngora, 1945), III, p. 13: “Así, toda donación es una liberalidad, pero no toda liberalidad es una donación, pues esta expresión general se aplica a todo acto generoso, a servicios prestados, como por ejemplo, la custodia gratuita de una cosa y este mismo calificativo se aplica a la emancipación de un hijo. En estos casos no hay verdadera donación, porque no existe la circunstancia de que una de las partes se desprenda de una porción de sus bienes con la cual se enriquezca la otra."; y más adelante trata directamente acerca del requisito del enriquecimiento de una parte y del empobrecimiento de la otra. Exige que en toda donación debe por tanto, pasar una porción de bienes a un patrimonio y su resultado debe ser que uno de los patrimonios disminuya, mientras que el otro aumente. Lo primero, lo identifica como el primer elemento: la enajenación; “[...] de manera que podemos sentar el principio de que la donación debe contener una enajenación; y tal es, en realidad, la base fundamental de toda donación [...]”, p. 23-32. Más adelante señala que se desprende de lo anterior: "[...] que donde no existe verdaderamente enajenación no existe tampoco donación, aunque el acto contenga otro elemento de esta última, como, por ejemplo, que el móvil del acto fuese conferir desinteresadamente un beneficio. Los casos de esta especie pueden clasificarse de la siguiente manera: 1 . El acto por el cual se expresa benevolencia no modifica la extensión de los bienes. 2 . Negligencia de un acrecentamiento 
porción de los bienes del donante pase de su patrimonio al del donatario. Esta transferencia la designa con la palabra "alienatio" (traducida como enajenación), que según el mismo el mismo Savigny, los juristas utilizaban ${ }^{6}$. De la postura de Savigny criticamos dos cosas: $i$ ) utiliza en forma abusiva el vocablo alienatio en materia de donación, el cual tiene un uso más técnico por la jurisprudencia; y ii) las fuentes en que se apoya para sostener el binomio depauperatio-locupletatio son casos que versan sobre donaciones entre marido y mujer, es decir, para resolver si aplicar o no la prohibición de las mismas; en consecuencia, no se puede generalizar ese régimen a la donatio inter vivos en general.

b) "Locupletatio-depauperatio" en De Robertis. La postura de Savigny influyó en la doctrina posterior, tanto para criticarlo como para seguirlo. Podemos observarlo en De Robertis ${ }^{7}$, quien en su artículo titula-

posible de riqueza, sin sacrificio de un derecho adquirido. 3. Abandono de una parte de los bienes, en virtud del cual se confiere a una persona un derecho distinto del derecho de bienes.", p. 24. En cuanto a los negocios como comodato, precario, depósito y el mandato, explica que a pesar de ser gratuitos "[...] en todos estos casos no existe donación porque la parte actora no modifica en manera alguna la cuantía de sus bienes. [...]". Y así, no constituyen donación los casos en que "[...] sin sacrificar un derecho adquirido, se renuncia a un aumento posible de riqueza sin constituir por consiguiente una donación [...]", p. 25.

${ }^{6}$ Ibíd., "He dicho (\$142) que el segundo elemento esencial de una donación verdadera, de una parte, el enriquecimiento; de otra el empobrecimiento. Este elemento de la donación, examinado atentamente, se subdivide en dos elementos distintos. Es preciso, en primer lugar, que una porción de los bienes pase de un patrimonio a otro; en segundo lugar, que la donación de por resultado que uno de los patrimonios disminuya, mientras que el otro aumente. El primero de estos dos elementos puede existir sin el segundo, y como ejemplo evidente citaré la venta de una casa en su justo valor: la casa pasa de un patrimonio a otro sin que ninguno de ellos se enriquezca ni empobrezca (a) [en nota cita D. 24, 1, 5, 8 y 16] designo con el nombre de enajenación al primero de estos dos tan distintos elementos; de manera que podemos sentar el principio de que la donación debe contener una enajenación; y tal es, en realidad, la base fundamental de toda donación". Las fuentes en que Savigny apoya su tesis, se encuentran en sus notas a pie de página desde la p. 22 en adelante; entre las que se encuentran fragmentos que pertenecen al libro rubricado De donationibus inter virum et uxorem (D. 24,1), en otras palabras, en su mayor parte a casos de donaciones entre marido y mujer; estos son: D. $24,1,5,8 ; 24,1,5,16 ; 24,1,58,2 ; 24,1,5,13$ y $14 ; 24,1,31,6 ; 24,1,31,7 ; 24,1,21,1 ; 24,1,17$ pr.; $24,1,49 ; 24,1,7,3 ; 24,1,15,1 ; 24,1,16 ; 24,1,17$.

${ }^{7}$ De Robertis, Francesco M., “Alienatio”, en Scritti varii di diritto romano (1939, reimp. Bari, Cacucci 1987), I, pp. 141-175; VOLTERRA, Edoardo, Instituzioni di diritto privato romano (1972, trad. Daza como Instituciones de derecho privado romano (Madrid, Civitas, 1986), p. 802. Expresa que los elementos que constituyen la donación en el denominado "objetivo" [...] enriquecimiento del sujeto beneficiado, con la correspondiente disminución patrimonial por parte del sujeto donante, enriquecimiento y 
do Alienatio, publicado en el año 1939, por un lado crítica a las nociones depauperatio-locupletatio exigidas por Savigny a la donación, debido a que resultan ser insuficientes para su configuración y además porque introducen confusión en el concepto de donación, en cuanto a que ésta es la causa y no el efecto económico (enriquecimiento-empobrecimiento). De Robertis enfatiza que la doctrina ha puesto especial atención en el aspecto más estático del fenómeno, el empobrecimiento del donante (depauperatio), es decir, la separación de la cosa donada de su titular ("il suo profisci"), lo que le parece un error, porque el efecto que se produce del aumento de un patrimonio necesariamente requiere que otro haya disminuido ${ }^{8}$. Luego explica ser probable que los clásicos tuviesen un concepto de patrimonio distinto al compilador, de allí que haya surgido esta cuestión?. A pesar de esta afirma-

disminución patrimonial respectiva que son la consecuencia de los efectos jurídicos del negocio realizado por el donante [...]"; Biondi, Biondo, Sucesión testamentaria y donación (trad. cast., Barcelona, Bosch, 1960), pp. 685-692.

${ }^{8}$ Ibíd., De Robertis, F., pp. 143-144: "Se infatti conseguenza di ongi donazione è l'aumento di un patrimonio in conseguenza della diminuzione di un altro, ocorre necessariamente considerare che tale effetto non si verifica in un sol tempo, ma è scindibile in due momento nettamente differenziabili: da una parte la separazione di alcunchè da una entità patrimoniale; dall'altra l'agregazione a nuevo, diverso patrimonio che ne rimene accresciuto.- Tale distinzione trova rispondenza precisa nelle fonti, le quali se in considerazione dell'effetto chiamano locupletatio il secondo questi momento, indicano il primo come un "de suo profisci", un "erogare de bonis". Ma la dottrina ha invece preferito fermare la propia attenzione sul resultato di questo distacco della cosa dal titolare, fissando l'aspetto statico del fenómeno: la depaupetatio del donante. Si è trattato però di un errore metodologico assai grave, se pure di limitare conseguenze: è ben vero infatti che nella maggior parte dei casi il risultato della costruzzione non cambia, poichè in effetti il depauperamento è la conseguenza normale di ogni "erogatio de bonis" quando questa sia preordinata a porre in essere una liberalità; ma quelche volta, almeno nella concezione classica, ciò non si verifica: è il caso della renuncia ad acquisto perchè altri ne benefici”. Esta idea la encontramos sólo tangencialmente en GUARINO, Antonio, La condanna nei limiti del possibile, Corso di diritto romano (Napoli, 1975), p. 48, cuando al tratar "il donator" expresa: "[...] Si ravvisava una donazione (cd. reale) in ogni trasferimento di proprietà che fosse stato operato allo scopo exclusivo di arricchire l'acquirente a spese dell'alienante; si ravvisava altresì una donazione una donazione ( $\mathrm{cd}$. liberatoria) in ogni atto di liberazione di un debitore dal suo obbligo di pagamento, che fosse stato operato dal creditore con renuncia al proprio soddisfacimento, e quindi allo scopo exclusivo di arrichire il debitore [...]".

${ }^{9}$ Ibíd., pp. 146-148: "La tesi poi che mentre i classici avrebbero vista una disminuzione di patrimonio nell' abbandono di una causa d'acquisto, i giustistinianei lo avrebbero negato [...] tanto più che essi, pur negando la disminuzione di patrimonio, hanno mantenuta la terminología classica e conservato il nome di donazione a negozi in cui essi più non vedono impoverimento del donante. Ma oltre a queste, altre difficoltà, di ordine esegetico, incontra la tesi sopra enunciata: a prescindere dalle critiche già mossile che hanno posto in rilievo come essa in definitiva non trovi conforto in testo alcuno 
ción, De Robertis no se detiene en la noción de patrimonio ${ }^{10}$, y continúa con que conviene evaluar otro elemento que es propiamente dinámico en una donación, y que Savigny denominó como alienatio ${ }^{11}$. Agrega que el binomio depauperatio-locupletatio sostenido por Savigny, aplicado al concepto de donación, resulta ser insuficiente. La depauperatio debe ser reemplazada por el término "alienatio" 12 . No desconoce que en el caso de la renuncia de un

veramente decisivo, essa si infrange contro due argomenti: 1) i classici considerarono donazioni vere e proprie quelle di res alienae, rispetto alle queali non si può certo sostenere che intervenga una disminuzione nel patrimonio del donante; 2) i testi solitamente citati a conforto della identità tra i concetti di donazione e di negozio che impoversce il donante e arrichisce il donatario (in quanto negano sia donazione dove nibil ex bonis deminuitur o non si verifichi un de suo profisci), conviene considerarli, come vedremo più oltre, in relazione alla mancanza di alienatio.- Nè a diversa conclusione si più pervenire ove si imposti il problema dal punto di vista dommatico: in ordine ai negozi con cui si rinuncia a favore di altri ad un acquisto, se si guardi al momento della separazione allo spossessamento della cosa da parte del titolare, e se ne consideri la mancanza, apparirà assai dubbio che un'alienatio si sia verificata in questi casi e che si abbia quindi una donazione, per quanto grande possa essere stata la intenzione di beneficare. Non cosi invece se si guardi all'impoverimento e arricchimento rispettivo: come infatti è stato già ossevato, la distinzione tra gli atti coi quali si diminuisce il proprio patrimonio e quelli con i quali si tralascia di aumentarlo sembra assai strana. Può bene infatti considerarse una disminuzione di patrimonio la cessione che si faccia alla moglie di una causa di acquisto in quanto essa stessa peri 1 diritto classico era indubbiamente un bene patrimoniale. Nè per la gravità degli effetti è possibile distinguere tra l'omissione di un atto di acquisto e gli positivi di alienazione".

${ }^{10}$ De Robertis, F., cit. (n. 7), pp. 148-149. "Riteniamo pertanto che l'elemento "patrimonio" -se pure non sua ininfluente per la determinazione del concetto di donazione- non riesce comunque a risolvere e a spiegare le questioni connesse agli atti di renuncia ad un acquisto con l'intento di compiere una liberalità: esso è troppo vago e generico, nè i giuristi romani si sono mai preoccupati di definirlo".

${ }^{11}$ Ibíd. p., 149; "[...] a torto posto in con cale: il momento dinamico del negozio, lo spossessamento della cosa da parte del titolare (erogatio) che bene il Savingy denominò "alienatio". Ad esso i moderni hanno preferito sostituire la "depauperatio", confondendo l'effetto con la causa, il momento statico con quello dinamico del fenómeno. E l'errore è tanto più evidente in quanto questo rapporto di causa ad effetto non è necesario ma solo normale, poichè come vedremo, nella donazione di cosa altrui si ha un'alienatio che non depaupera il donante; e, per converso, nella renuncia ad un acquisto i classici hanno visto qualche volta un impoverimento, pur escludendo fosse intervenuta una "alienatio".

${ }^{12}$ Ibíd., p. 150: "Ma una volta rilevata la insufficienza dell'elemento depauperatiolocupletatio a determinare il concetto di donazione, premettiamo subito che, secondo quanto avremo modo di stabilire fra poco, il primo termine del binomio (la depauperatio) ha da essere sostituito con l'alienatio, si da configurare l'arrichimento del donatario come conseguente non dal depauperamento del donante, ma dall'alienatio che questi avesse fatta a favore di quello di alcunchè di sua pertinenza”; más adelante agrega que: "Conviene pertanto riconoscere la insufficienza dommatica ed esegetica della indentità 
"acquisto" no habría tal empobrecimiento del donante, por lo que no se daría el elemento denominado alienatio, pero agrega a propósito de la revisión del pasaje D. 50,16,28 (Paul., 21 ed.) ${ }^{13}$ que el concepto imperante sobre actos voluntarios de los que su titular se separaba de la cosa en dominio, evolucionó en forma fatigosa hasta llegar a abarcar casos en que la voluntariedad ya no era de cosas sino de deudas ${ }^{14}$. Sin embargo, De Robertis opina que los casos de renuncia o repudiación de una herencia, o de un legado (D. 38,5,1,6) no constituyen alienatio $^{15}$. Cuando pasa a examinar concretamente que la

fra donazione e negozio che depaupera il donante e arricchisce il donatario, sia peri 1 diritto classico che peri l diritto giustinianeo". "[...] si da configurare l'arrichimento del donatario come conseguente non dal depauperamento del donante, ma dall'alienatio che questi avesse fatta a favore di quello di alcunchè di sua pertinenza".

13 "Alienationis" verbum etiam usucapionem continet: vix est enim, ut non videatur alienare, qui patitur usucapi. Eum quoque alienare dicitur, qui non utendo amisit servitutes. Qui occasione adquirendi non utitur, non intellegitur alienare: veluti qui hereditatem omittit aut optionem intra certum tempus datam non amplectitur" ("La palabra "enajenación" comprende también la usucapión porque difícil es que no parezca que enajena el que consiente que se usucapía. Se dice que enajena también el que no usándolas pierde servidumbres. El que no utiliza la ocasión de adquirir no se entiende que enajena, como el que prescinde de una herencia, o no se aprovecha de la opción que se le dió, dentro de cierto tiempo").

${ }^{14}$ Cfr. De Robertis, F., cit. (n. 7), p. 151; “[...] il concetto tradizionale di trasferimento della proprietà da uno ad altro titolare (translatio dominio), dovuto, come sembra, al turbamento portato nella materia dai bizantiniri construendo la figura classica dell'alienatio come quella di "qualunque atto per il quale la cosa veniva rimossa dal proprio dominio in modo che potesse passare nel dominio altrui"; y agrega: "È in definitiva il distacco voluntario di alcunchè dal titolare: in questa concezione propria e può comrendersi certo l'usucapione; ma la giurisprudenza, sotto la spinta di esigenze pratiche ben evidente, si apoderò ad estenderne il concetto e all'alienatio vediamo fra l'altro ricondotta l'usucapio, o meglio il pati usucapi: [...]" y aquí cita el texto de Paulo (21 ed.) el D. 50,16,28 pr.

${ }^{15}$ Ibíd., pp. 155-156; añade a propósito de D. 27,9,5 pr. y 8 (Ulp., 35 ed.): "Si noti tuttavia che il problema non sussisteberebbe ove, seguendo l'opinione di alcuni studiosi, si ritenesse che il giurista avesse presente non la ipotesi generica del rifiuto del legato, ma quella specifica della repudiatio del legado per vindicationem, di cui l'oggetto secondo la dottrina sabiniana, passava inmediatamente in proprietà dell'onorato: a questa particolarità si riferirebbe l'espressione "cum res sit pupillo".- tale soluzione, quantunque comoda in sommo grado per la nostra tesi, ci lascia tuttavia perplessi: che il giurista avesse presente il caso del legado per vindicationem non si può affermare che sulla base dell'inciso sopra indicato, di interpretazione del resto dubbia assai. Tutto il tenore del passo sembrerebbe affermare il contrario: Ulpiano non examina un caso pratico, ma in linea di principio si adopera a stabilire le ipotesi in cui, verificandosi o non verificandosi un'alienatio, si doveva far luogo o meno alle formalità stabilite dall'oratio Severi. E per tal modo bisognerebbe ammettere che se egli non generalizaba in ordine alla renuncia al legato in genere, esaminava quest' ultima in relazione alle varie forme di legato e che si 
alienatio puede constituir otro elemento de la donación, se pregunta si tal fue o no el parecer de los juristas. A esto responde, que como resultado de una abstracción dogmática realizada por Savigny emerge la alienatio del pensamiento de los juristas romanos, así expresa: “[...] ma si tratta di una intuizione felice che trova riscontro perfettto nelle fonti" ${ }^{16}$.

debe ai compilatori la soppressione della parte del testo relativa alle altre forme. Ma una ipotesi di questa fatta urta contro l'inciso "esse enim et hanc alienationem", inesplicabile, ove il giurista avesse data diversa soluzione agli altri casi”. Más adelante expresa que: "E, in definitiva, per configurare come alienatio questo caso converrebbe rinunciare ad uno dei risultati più attendibili della critica esegetica recente, secondo la quale l'lienatio classica non avrebbe avuta ad oggetto il diritto, ma la cosa, poichè in caso di renuncia non si verificherebbe che la separazione del diritto.”, pp. 156-157. Más adelante expresa: "Resta pertanto confermato che il diritto classico mantenne fermo rigidamente il principio che la omissione di un acquisto, il negozio con cui si tralasciava di aumentare il proprio patrimonio, no poteva configurare un'alienatio" (p. 160).

${ }^{16}$ Ibíd, p. 161. Y continúa: "Ecco infatti Ulpiano presentarci l'alienatio come uno dei presuposti della donazione [...]" y cita la última parte del D. 24, 1, 3, 8 "Si servus meus, cuius usus fructus alienus est, donet uxori meae ex eo peculio, quod ad me non pertinebat, vel homo liber bona fide mihi serviens, an valeat donatio, quaeritur. Et in libera quidem persona utcumque admitti potest donatio: ceterae enim personae alienationem peculii ut donent non habent" ("Si con el peculio que no me pertenecía hiciera donación a mi mujer con el esclavo mío, cuyo usufructo es de otro, o un hombre libre que de buena fe me prestara servidumbre se pregunta si será válida la donación. Y a la verdad, en cuanto a una persona libre, de cualquiera manera puede admitirse la donación; porque las demás personas no tienen la enajenación del peculio para hacer donación"). Más adelante agrega que "È bensì vero che in tema di donazioni non ricorrono di frequente i richiami diretti all'alienatio; ma ciò è dovuto senza dubbio all'opera dei compilatori i quali, come vedremo in seguito, ne hanno soppressa la mencione, poché, avenido estezo el concepto di donaciones fino a prescindiré da puesto elemento, vi recomprándonos anche i casi in cui i clásica, apunto per non esterco aliena tío, escludevano la donazione. [...] E altrove si allude a "deponere de patrimonio", "erogare de bonis", con evidente riferimento al lato attivo, dinamico del fenomeno, che, concratandosi in uno spossessamento, presupone l'acquisto e non è quinde applicabile alle omisioni.", p. 162. Posteriormente establece que los puntos fundamentales de la reconstrucción de la donación en el derecho romano clásico se deben tener en cuenta dos premisas fundamentales: i) “[...] non v'era alienatio, cioé separazione di una cosa sal titolare, nella renuncia ad una causa d'acquisto o nella omissione di esso"; y ii) "che fra gli elementi richiesti a qualificare giuridicamente la donazione era anche l'alienatio. Da queste due premesse discende come logica conseguenza che nella renuncia ad acquisto i classici non potevano ravvisare donatio.”, p. 164. enunciados los anteriores principios De Robertis pasa a revisar el texto del D. 24, 1, 5, 16, perteneciente a Ulpiano ( 7 dig.) expresa: "È certo tuttavia che il testo fin da un primo esame presenta elementi rilevantissimi di sospetto: esso afferma la validità fra coniugi di questa forma di do- 
Esto explica que De Robertis vuelva al uso excesivo de la noción de

nazione (donatio valet); ma i classici, non bisogna dimenticarlo, hanno consentita la donazione fra coniugi solo per alcune "causae" specificamente determinate: il testo invece prescinde da queste e ci presenta la eccezione in funzione di un diverso criterio: il mancato depauperamento del donante" (p. 166). Luego a propósito del caso del D. 24,1,5,13 y 14, señala que: "[...] è pacifico che manchi uno dei presupposti della donazione; è credibile che i giuristi romani non vi abbiano posto mente, quando poi, come abbiamo già rilevato, allo scopo di dare a questo o quel negozio la quealificazione giuridica appropriata, non mancano nel caso di chiedersi an alienatio sit. Nel frammanto di cui sopra il giurista (una volta ammessa come vedremo più oltre la interpolazione dell inciso precedente relativo al depauperamento) assume a termine di riferimento il 'de patrimonio deponere': qui, come negli altri casi in cui è parola di erogare de bonis, di de suo profisci, si releva la preoccupazione appunto per lo spossessamento della cosa. Qui più che al depauperamento sembra si guardi alla separazione della cosa del titolare; al distacco di un bene da un patrimonio perchè óptese passare in un altro. In questo caso in cui, dato il carattere di caso limite, l'impoverimento poteva determinarse anche indipendentemente da una alienatio, non giovava guardare alla deminutio de bonis per desumerla, come pare si faccia in qualche altro caso; ma convenida Proxy il problema nei suoi termini precisi e riferirsi al momento dinamico del negozio. Ma giustiniano prescinde da questo requisito in tema di donazioni, tal che i compilatori si sono adoperati a farne sparire le tracce, sopprimendone i vari accenni e denominando donazioni negozi a cui la giurisprudenza classica, appunto in considerazione dell'alienatio, aveva negato tale quelifica. Per essi il mancato acquisto poteva bene dar luogo a donazione quando fosse stato preordinato a scopo di liberalità. Nel rimaneggiare i testi però non hanno saputo impedire che fra le suture conseguenti alla eliminazione dei richiami all'alienatio trasparisse quea e là il pensiero dei classici. [...] Nè è possibile con il Savingy pensare che in questo caso cin si trovi davanti ad un uso improprio del vocabolo "donatio": fin dall'epoca di Giuliano noi vediamo la giurisprudenza adoperarsi a precisare il concetto di donazione fissando la terminologia e reagendo contro ogni uso volgare del termine. Non è quindi credibile che ancora all'epoca di Ulpiano si continuasse a perpetuare l'equivoco in un tema, come quello dei rapporti tra coniugi, in cui ad ogni piè sospinto doveva sorgere il problema "an donatio sit" [...]." Al final concluye su artículo con las siguientes palabras: "Concludendo pertanto, dobbiamo ritenere che i giuristi classici, poichè non concepivano donazione senza il materia distacco dell'oggetto dal titolare, non pare si siano preoccupati della diminuzione patrimoniale conseguente alla donazione (e sempre che l'unico frammento in cui ciò si verifica non sia statu manomesso dai compilatori) che per determinare a posteriori l'intervento o meno di una "alienatio". Pare invece che tenessero conto della locupletatio. "Nel caso pertanto di renuncia ad un acquisto con l'intenzione di beneficiare altri negarono la donazione per la mancanza di alienati. Da tali elementi invece prescindette Giustiniano, il quale elevò l'animus, l'intenzione liberale, a elemento decisivo per la determinazione del negozio e per tal guisa potente porre in non cale gli altri requisiti richiesti dal diritto classico: l'alienatio e, pare, gli efetti patrimoniali della liberalità. Allargato così il campo delle donazioni, egli si trovò 
alienatio o enajenación, ahora sin perjuicio de unirla a la noción pauperatio, que en definitiva no la distingue del otro efecto económico (locupletatio), sino sólo para decir que todo el fenómeno de la donación implica un efecto estático sufrido por el donante en su patrimonio (pauperatio) y el otro es el efecto dinámico el enriquecimiento (locupletatio); ambos son efectos económicos de la donación, pero que los sintetiza en alienatio y lo exige como un elemento de la donación. Nos parece que su planteamiento es oscuro y además reincide en el uso excesivo que criticábamos en Savigny ${ }^{17}$.

c) "Locupletatio-depauperatio" en Archi. Después de tratar a Savigny y De Robertis, interpelamos la postura de Archi sobre la materia en su obra La donazione. Corso di diritto romano. Al principio, aparentemente, su posición pareciera que sigue el pensar de De Robertis, en cuanto a la crítica que éste formulaba, sobre la insuficiencia de los elementos depauperatiolocupletatio para establecer el concepto de la donación; y también en cuanto a que ambos son efectos económicos y no jurídicos de la misma. Pero a continuación refuta la tesis esgrimida por De Robertis, de unir ambos elementos en una sola noción "alienatio" (enajenación) ${ }^{18}$, y exigirla como elemento de la donación, porque tras este concepto existen algunas hipótesis de donaciones que deja fuera ${ }^{19}$, por ejemplo, la renuncia a un crédito. Además, agrega que

a dover risolvere il problema della liceità fra coniugi di alcuni negozi che la giurisprudenza classica aveva considerati validi solo perchè escludendo si trattase di donazioni, aveva rimossa la case per l'aplicazione del divieto. Giustiniano mantenne fermo nella sostanza il regolamento clásico partendo dal principio che fra coniugi è donatio licita quella che o non depaupera il donante o non arricchisce il donatario" (pp. 174-175).

${ }^{17}$ Adhieren aún a la tesis del binomio depauperatio-locupletatio algunos autores como: García Garrido, Manuel, Derecho privado romano. Acciones, casos, instituciones (Madrid, Dykinson, 1991), pp. 461: "Se concibe la donación como acto de liberalidad que supone un empobrecimiento del donante y un enriquecimiento del donatario. En este sentido, la donación clásica no es un negocio típico sino la causa de un acto de atribución patrimonial, o causa lucrativa [...]"; Di Pietro, Alfredo, Derecho privado romano (2a edición, Depalma, Buenos Aires, 1999), p. 263.

${ }^{18}$ ArCHI, Gian Gualberto, La donazione. Corso di diritto romano (Milano, Giuffrè, 1960), p. 81: "Nè si obietti che il Savingy parlava a proposito della donatio di alienazione e che quindi vi è un autorevole precedente a una simile definizione. Infatti il Savingy, usando questo termine avvertiva subito il lettore che egli lo intendeva in senso più vasto di quello corrente, che era un senso più ristretto coincidente con quello romano di alienatio. [...]".

${ }^{19}$ Ibíd., "Come si vede, vi è una sostanziale differenza tra la posizione del Savingy e quella del De Robertis. Il primo dava al termine un significato suo proprio e convenzionale, però avvertendo il lettore di non lasciarsi ingannare da ciò. Il secondo invece pone l'equazione tra alienazione e donatio, attribuendo quindi alla prima il suo tecnico significato. Tutto questo è assai importante, perchè, mentre il Savigny poteva poi affermare sulle fondamenta della sua definizione che erano donazioni in dando, in obligando e in 
lo anterior resulta forzoso debido a dos razones: i) que las fuentes esgrimidas por De Robertis no son suficientes para sostener su postura ${ }^{20}$; y ii) además que estas no guardan relación directa con la donación, sino que pertenecen a otra materia: las facultades que compete a un alieni en la administración del peculio profecticium ${ }^{21}$. Por tanto, para la jurisprudencia la palabra alienatio tiene un uso más técnico, del cual no es posible extrapolarlo a que sea un elemento que configura la donación.

d) Locupletatio-depauperatio en d'Ors y otros autores. La postura mayoritaria acerca de esta cuestión se inclina, principalmente, con la posición de $\mathrm{Archi}^{22}$. Entre aquellos que le siguen es pertinente mencionar

liberando, il De Robertis con consequenzialità afferma invece che, per aversi donazione, debe esserci il materiale distacco dell'oggetto dal titolare".

${ }^{20}$ Cfr. D. 24,1,3,8; 39,5,7; 20,3,1,1; 2,14,28,2.

${ }^{21}$ Archi, G. G., La donazione, cit. (n. 18), p. 81: "Ho il timore che ci sia dimenticati di vagliare una simile conclusione alla luce di tutti quei numerossimi passi delle fonti, che parlano di donazione e nei quali non può certo dirsi che si discutano fattispecie 'con materiale distacco dell'oggetto'. Si pensi alle donazioni promissorie; si pensi alle liberatorie e credo che si converrà con me nel dubitare che la nuova ipotesi possa risolvere quel problema, che auspiciava di eliminare"; p. 936: “Acertata l'estraneità delle elemento depauperatio-locupletatio al concetto classico di donazione, deve qui dirsi che è inaccoglibile anche il recente tentativo, pur esattamente partito dall'analisi delle insufficienze della dottrinadi Savigny, di sostituire al termine depauperatio quello di alienatio, concezione questa che, contro ogni evidenza delle fonti, finirebbe per restringere le ipotesi di donazione a quelle in cui è riscontrabile un distacco materiale di entità patrimoniali dal soggetto titolare. D'altra parte in D. 24,1,38, alienatio ha il significato di administratio (complesso dei poteri spettanti sul peculio alle persone in potestate; cfr. D. 39,5,7; D. 20,3,1,1; D. 2,14,28,2) (e d'altra parte D. 24,1,3,8 è sospettato di itp.). D. 48,8,12, reca il termine alienatio, ma in luogo sospetto, comunque in relazione al gerere fraudationis causa: D. 49,14,45 pr. (alienazioni in fraudem fisci) e D. 27,10,17 (alienazioni donationis causa contrapposte a quelle ad administrationem negotiorum), si obtiene solo il modesto risultato di accertare che vi possono essere alienazioni donationis causa e non certo che la donazione si concreta sempre in una alienazione; quanto poi a D. 50,16,67, è del tutto anodino; queanto infine ai testi epigrafici, in cui compare l'espressione venum dare fiduciare vel donum dare vel ullo modo alienare [...], si può solo dire che se il donum dare rientra nella tipica alienatio, ciò non significa che ogni donatio sia un donum dare (cioè, donazione reale) e quindi una alienatio". Véase El MISMo, La donazione: diritto romano, en Enciclopedia del Diritto (Milano, Giuffrè, 1964), XIII, pp. 935-937.

${ }^{22}$ Biondi, Biondo, Sucesión testamentaria y donación (trad. cast., Barcelona, Bosch, 1960), pp. 649-662; El Mismo, Il concetto di donazioni, en Scritti giuridici (Milano, Giuffrè, 1965), III, p. 648. Allí critica lo sostenido por Savigny y expresa: "A parte la ovvia limitazione ai rapporti patrimoniale ed alla esatezza del concetto di donazione come arricchimento, che discutiremo un seguito (n. 9; 16), quella nozione resulta imperfecta sotto vari aspetti”; y más adelante, después de haber estudiado los requisitos y la prohibición de las donaciones entre cónyuges, señala que una consecuencia de 
estas es que: "Nei rapporti tra coniugi la legge proibisce non la donazione, concepita come atto di liberalità, ma il fenomeno dell'arricchimento di un coniuge a detrimento dell'altro, e quinde l'obbietto di tale divieto, appunto perchè ha una particolare ragione di essere, non si può elevare a concetto generale di donazione" (p. 698). Cfr. AlbaneSE, Bernardo, Rec. a Archi, La donazione. Corso di diritto romano [1960], en Scritti Giuridici (Palermo, Palumbo, 1991), II, pp. 251-259; Fuenteseca, Pablo, Derecho privado romano (Madrid, E. Sánchez A. Gráficas, 1978), p. 586, en relación a los dos elementos (objetivo y subjetivo) que suelen caracterizar la doctrina a la donación indica lo siguiente: "Objetivamente para que exista donatio ha de tener lugar una atribución u otorgamiento de bienes del donante al donatario de modo que el primero sufra una disminución patrimonial a favor del segundo, que obtendrá un lucro. No se trata de la simple ventaja que un hecho gratuito puede acarrear a otra persona, sino que se necesita de un hecho jurídico lucrativo para el donatario. No es lo mismo dar alimentación gratuitamente que renunciar a un derecho dejando de extinguir una servidumbre. Podíamos decir que la donatio comprende todo hecho jurídico lucrativo para el donatario. [...]"; Giunti, Patricia, Donazione, en Digesto delle discipline privatistiche, Sez. Civile (Torino, UTET, 1991), VII, p. 164, expresa que: “[...] L'equivalenza dell'atto liberale con quello che arricchisce il beneficiario depauperando il beneficiante affiorava già nella Pandettistica del secolo scorso, ispirata agli insegmenti del Savigny che proprio nel binomio locupletatio-depauperatio coglieva l'intima essenza strutturale della causa donationis, al di là delle svariate modalità eesplicative. Ma la moderna dogmatica, attenta più ai connotati giuridici che non ai risvolti economici dell'istituto, ha avvertito l'insufficienza di un simile requisito di fronte ad ipotesi di renuncia omisiva concretanti una donazione senza impoverimento del donante; estraneo altresi ai commenti ad legem Cinciam, il criterio locupletatio-depauperatio sembra trovare applicazione esclusiva nel ristretto campo delle donazione fra coniugi, del cui divieto individua il raggio di azione sostituendosi al fattore 'gratuità', decisivo nell'ottica del plebiscito cincio”; GuZmán Brito, Alejandro, Derecho privado romano (2a edición, Santiago, Legal Publishing Chile, 2013), p. 683, en materia de donaciones entre cónyuges manifiesta: "Para que una donación directa o indirecta entre cónyuges, sin embargo, se vea afectada por la prohibición, menester es que el donante se haga más pobre (pauperior) y más rico el donatario (locupletior). No es suficiente, pues, la mera atribución patrimonial en que toda donación en sí misma ya consiste, si ella no va acompañada del mencionado efecto económico en los respectivos patrimonios. En consecuencia, casi podría decirse que lo prohibido es el empobrecimiento-enriquecimiento entre cónyuges derivados de una donación.- La posibilidad de separar conceptualmente las nociones de atribución por un lado, de las de empobrecimiento y enriquecimiento por otro, deriva de tratarse de conceptos de naturaleza diferente: mientras la primera tiene carácter estrictamente jurídico, las segundas consisten precisamente en un efecto económico. Para que haya empobrecimiento se exige existir efectivo gasto de lo propio, y no es bastante omitir una adquisición posible; y el enriquecimiento tiene lugar cuando el valor adquirido aprovecha efectivamente, sin que resulte suficiente haber evitado un gasto. En todo caso, estos efectos deben haberse producido al tiempo de la litis contestatio"; Grosso, Giuseppe, Rec. a G.G. Archi, La donazione, Corso di diritto romano (1961), en Scritti storico-giuridici (Torino, Giappichelli, 2001), IV, pp. 494-495; Luzzatto, Giuseppe Ignazio, Donazione e liberalità. Evoluzione storica di un istituto romano e suoi riflessi 
a Álvaro d'Ors, a propósito de su distinción entre los términos, por un lado el de "ventaja económica", y por otro, el "lucro en la donación", explica que el primero apunta al beneficio que puede obtener el donatario como consecuencia de la donación; y el segundo es el efecto propiamente jurídico de ella y que es denominada como lucratividad ${ }^{23}$. De esta manera para d'Ors no sería un elemento de la donación el enriquecimiento del donatario y tampoco el denominado empobrecimiento, como era afirmado por Savigny y posteriormente por De Robertis, con el binomio depauperatio-locupletatio para el primero, y alienatio-locupletatio para el segundo (que más parece fusionar ambos en el primero, alienatio).

Además, los autores ${ }^{24}$ opinan que este tema en las fuentes se relaciona más con una clase de donación, aquellas que son inter vir et uxor, postura que también sostiene Archi.

sulla dogmatica odierna, en RDPC., 14 (Milano, 1960), p. 1587; Miluel, Joan, Curso de derecho romano (Barcelona, PPU, 1987), p. 405-406. A propósito de precisar los requisitos propios de la donación (la que define como un acto gratuito de atribución patrimonial) plantea que uno de los problemas más complejos es si: “[...] ¿supone, siempre, un empobrecimiento y enriquecimiento, correlativos de donante y donatario, respectivamente? Desde, Savigny hay muchos autores que responden afirmativamente a esta pregunta. Pero, en realidad, a poco que pensemos nos daremos cuenta quel a (errata: debería decir, que la) donación como causa donationis no tiene necesariamente por qué coincidir con un empobrecimiento y enriquecimiento. Así, evidentemente, la donación puede funcionar como causa donationis en la usucapión de cosa ajena y, sin embargo, no hay aquí un empobrecimiento del donante. En realidad, como se observa justamente la doctrina más autorizada el requisito del empobrecimiento-enriquecimiento aparece en las fuentes en conexión con un tipo de donaciones: las donaciones entre cónyuges. Se prohíben, únicamente, las donaciones entre cónyuges con el correlativo enriquecimiento del otro. A la inversa, los clásicos admiten la usucapión que tiene por causa donationis una donación de cosa ajena entre cónyuges, ya que no hay a qué empobrecimiento del cónyuge donante (así D. 41,6,3)".

${ }^{23}$ D'Ors, Álvaro, Derecho privado romano (9a edición, Pamplona, EUNSA, 1997), p. 394: "Debe distinguirse entre los actos lucrativos y los gratuitos: sólo aquéllos pueden ser donación. El lucro supone una adquisición definitiva (capere: D. 50,17,51), y puede producirse también por la renuncia abdicativa de un derecho, e incluso por un comportamiento de hecho, como dejar de usar una servidumbre para que se extinga por non usus $(24,1,5,6)$, construir (CI. 3,32,3,1, del 213) o sembrar (D. 39,5,14) en fundo ajeno sin pretender indemnización $(\$ 168)$. Este concepto jurídico de "lucro" debe distinguirse del de "ventaja económica", en la que se puede incluir el mutuo sin interés, la venta o arriendo a bajo precio, el evitar un gasto previsible, etc.; cfr. D. 3,6,2, al analizar el accipere pecuniam calumniae causa".

${ }^{24}$ Véanse en este sentido: Biondi, B., cit. (n. 22), p. 674: expresa "el criterio del enriquecimiento es el centro de toda la doctrina sobre las condiciones entre cónyuges"; Giunti, P., cit. (n. 22), p. 164. 


\section{Locupletatio-depauperatio en la jurisprudencia romana.}

Veamos a continuación lo qué entendió la jurisprudencia en aquellos textos en los que aparentemente tratan sobre el binomio locupletatio-depauperatio. Cuya selección de fragmentos corresponden a Pomponio, Terencio Clemente, Papiniano y a Ulpiano.

Pomponio (24 ad Quintum Mucium) D. 41, 6, 3 "Si vir uxori, vel uxor viro donaverit, si aliena res donata fuerit, verum est, quod Trebatius putabat, si pauperior is, qui donaste, non fieret, usucapionem possidenti procedere"25. Plantea que si la mujer dona al marido una cosa ajena, ella (donante) no se hace en ningún caso más pobre y el marido (donatario) como poseedor podrá adquirirla mediante usucapión. En consecuencia, para Pomponio en este caso la donación existe y sería válida, aunque fuese entre cónyuges, debido a que falta el requisito de ésta, que la donación empobrezca al donante. Además, tampoco vemos que haya un enriquecimiento por parte del donatario a costa del otro cónyuge, exigencia que, por ejemplo, Savigny reclamaba, esto en general para toda donación, según el binomio locupletatio-depauperatio.

Terencio Clemente (5 leg. Iul.Pap) D. 24, 1, 25 expresa en la parte: "Sed et si constante matrimonio res aliena uxori a marito donata fuerit, dicendum est, confestim ad usucapionem eius uxorem admitti, quia et si non mortis causa ei, non impidiretur usucapio; nam ius constitutum ad eas donaciones pertinet, ex quibus el locupletior mulier, etpauperior maritus in suis rebus fit. Itaque licet mortis causa donatio interveniat, quasi inter extraneas personas fieri intelligenda est in ea re, quae, qui aliena est, usucapi potest"26. Este fragmento versa sobre el mismo caso que planteaba Pomponio, con la diferencia que en éste es el marido quien dona una cosa ajena a su mujer; derechamente en la parte "nam ius constitutum ad eas donacionespertinet, ex quibus el locupletior mulier, etpauperior maritus in suis rebusfit” son nombrados por Terencio Clemente los requerimientos de la donación entre marido y mujer: el enriquecimiento por una parte y el empobrecimiento de la otra. Ellos faltan porque la cosa donanda es aliena, y por tanto, al no existir un detrimento en el patrimonio

25 "Si el marido a la mujer, o la mujer al marido le hubiere donado una cosa, es verdad, si hubiere sido donada una cosa ajena, lo que opinaba Trebacio, que, si no se hiciera más pobre el que la hubiese donado, procedía la usucapión a favor del que la poseía”.

26 "Pero también si durante el matrimonio hubiere sido donada por el marido a la mujer una cosa ajena, se ha de decir, que desde luego es admitida la mujer a la usucapión de la misma, porque si no se la hubiera donado por causa de muerte, tampoco se impediría la usucapión; porque el derecho establecido se refiere a las donaciones por las que la mujer se hace más rica, y el marido más pobre en sus propios bienes. Y así, aunque medie donación por causa de muerte, se ha de entender que se hace como entre personas extrañas, tratándose de cosa que, porque es ajena, puede ser usucapida”. 
de uno de los cónyuges a favor del otro, se siguen las reglas de las donaciones entre personas extrañas, es decir, a las que dichos efectos no le son exigidas.

Papiniano D. 35, 2, 15, 5 (13 resp.): "Ex donationibus in uxorem collatis quod heres eius reddere viro cogitur, in bonis mulieris non erit. Nam ita fit locupletior, ut tanto pauperior esse videatur: quod autem heres inde minuit, viro non perit" ${ }^{27}$. Según lo expuesto, los herederos de la mujer son obligados a devolverle al marido sólo aquellos bienes en que se hubiese hecho más rica y en lo que el marido se hubiese empobrecido. Observamos que de la misma manera que Pomponio y Clemente Terencio mencionaban como exigencias de las donaciones inter virum et uxorem, el enriquecimiento del donatario y el empobrecimiento del donante es Papianiano quien también los enuncia ahora, que expuesto sí se dan.

A Ulpiano se le atribuyen los siguientes fragmentos:

D. 24, 1, 5, 8 (32 Sab.): "Concessa donatio est sepulturae causa: nam sepulturae causa locum marito ab uxore vel contra posse donari constat et si quidem intulerit, faciet locum religiosum. Hoc autem ex eo venit, quod definiri solet eam demum donationem impediri solere, quae et donantem pauperiorem et accipientem faciet locupletiorem: porro bic non videtur fieri locupletior in ea re quam religioni dicavit. Nec movit quemquam, quod emeret, nisi a marito accepisset: nam etsipauperior ea fieret, nisi maritus dedisset, non tamen idcirco fit locupletior, quod non expendit" ${ }^{28}$. El caso que ahora observamos, trata de cuando entre cónyuges lo que se donan es una sepultura. La cuestión es si hay o no donación, porque se entiende que este acto no hace más pobre a uno y más rico al otro (depauperatio- locupletatio) puesto que lo donado es una res extra comercium, la que no es susceptible de tráfico alguno, y por ende, tampoco de ganancia. Por lo tanto, al no poder obtener ninguno de los cónyuges (donante-donatario) una ventaja económica con la donación, ella es válida como si lo fuese entre personas extrañas.

27 "Lo que de las donaciones hechas a la mujer es obligado su heredero a devolverle al marido no estará entre los bienes de la mujer; porque así se hace más rica, de suerte que en otro tanto se considere que es más pobre; mas lo que de allí disminuyó el heredero, no se pierde para el marido".

${ }^{28}$ Lenel, Otto, Palingenesia iuris civilis (1889, reimp. Graz, Akad. Druck u. Verlagsanst., 1960) en adelante, Lenel, O., Paling., II, frag. 2.765 (col. 1.139): “Está admitida la donación por causa de sepultura; porque consta que por causa de sepultura puede donarse por la mujer un lugar al marido o al contrario; y si verdaderamente hubiere hecho un enterramiento, hará religioso el lugar. Mas esto provienen de lo que suele decirse, que se suele prohibir solamente aquella donación, que hace más pobre al donante, y más rico al que la recibe, pero a la verdad, no se considera en este caso que se hace más rico con cosa que dedicó a la religión. Y no hace variar decir que lo había comprado, si no lo hubiese recibido de su marido; porque aunque ella se haría más pobre, si el marido no se lo hubiese dado, no se hace sin embargo más rica por esto, porque no gasta”. 
D. 24, 1, 5, 13 (32 Sab.): "Si maritus heres institutus repudiet hereditatem donationis causa, Iulianus scripsit libro septimo decimo digestorum donationem valere: neque enim pauperior fit, qui non adquirat, sed qui de patrimonio suo deposuit. Repudiatio autem mariti mulieri prodest, si vel substituta sit mulier vel etiam ab intestato heres futura"29. El marido que repudia una herencia no se empobrece, porque no realiza un gasto que salga de su propio patrimonio, y si ésta llegase a favorecer a su mujer, la donación para todos los efectos existió y fue válida, ya que no se configuró la donación inter virum et uxorem; el marido no se hizo más pobre y la mujer no se hizo más rica, de allí que no se cumpla con el presupuesto de la prohibición entre cónyuges de hacerse donación.

D. 24,1,5,16 (32 Sab.): "Cum igitur nibil de bonis erogatur, recte dicitur valere donationem. Ubicumque igitur non deminuit de facultatibus suis qui donavit, valet, vel, etiamsi deminuat, locupletior tamen non fit qui accepit, donatio valet" ${ }^{30}$. Dentro del mismo contexto de los pasajes que ya antes y a continuación mencionaremos (D. 24,5,1,5,15 y 17) tratan del empobrecimiento del donante como del enriquecimiento del donatario en relación a las donaciones entre vir et uxor ${ }^{31}$. Ulpiano entiende el empobrecimiento como una erogación (erogatio), es decir, un gasto, desembolso o destrucción, en el sentido genérico del vocablo. Pero si afinamos un poco, podríamos decir que estos actos tienen relación con la facultad de disponibilidad jurídica total, que como sabemos es la máxima forma de aprovechamiento de las cosas que tiene el dueño. Pues bien, si volvemos al texto, Ulpiano sostiene que si no

${ }^{29}$ Lenel, O., Paling., II, frag. 2.765 (col. 1.139): "Si instituido heredero el marido, repudiare por causa de donación una herencia, escribió Juliano en el libro décimo séptimo del Digesto, que válida la donación; porque no se hace más pobre el que no adquiere, sino el que gastó de su patrimonio. Mas la repudiación del marido aprovecha a la mujer, ya si la mujer hubiera sido sustituida, ya también si hubiera de ser heredera".

${ }^{30}$ Lenel, O., Paling., II, frag. 2.765 (col. 1.140): “Más cuando no se gasta nada de los bienes, con razón se dice que es válida la donación. Así, pues, siempre y cuando no disminuye sus propios bienes el que hizo la donación, es válida esta, o aunque los disminuya si no obstante no se hace más rico el que la recibe, es válida la donación”.

${ }^{31}$ Esto lo afirmamos, porque el pasaje que inmediatamente menciona Lenel en su Palingenesia se refiere justamente a las donaciones entre cónyuges: Lenel, O., Paling., II, frag. 2.765 (col. 1.140) D. 24,1,5,17 (Ulp., 32 Sab.): "Marcellus libro septimo digestorum quaerit, si mulier acceptam a marito pecuniam in sportulas pro cognato suo ordini erogaverit, an donatio valeat? et ait valere nec videri locupletiorem mulierem factam, quamvis mutuam pecuniam esset acceptura et pro adfine erogatura" ("Pregunta Marcelo en el libro séptimo del Digesto, ¿será válida la donación, si la mujer hubiere gastado en espórtulas para un cargo por un cognado suyo el dinero recibido de su marido? Y dice que es válida, y que no se considera que la mujer se hizo más rica, aunque hubiese de recibir dinero en mutuo, y gastarlo a favor de un afin"). 
hay un desmedro en el patrimonio por el gasto que se ha efectuado mediante una donación, y el consecuente enriquecimiento, se dice que es válida la donación. Este fragmento no se entiende si no comprendemos el contexto en el que parece citado y para esto Lenel es quien nos da luces para tratarlo, ya que en su reconstrucción continúa con el D. 24,1,5,17, que justamente versa sobre las donaciones entre cónyuges, de allí que la donación sea válida, al no configurarse esta clase.

D. 24,1,5,18 (32 Sab.): "In donationibus autem iure civili impeditis hactenus revocatur donum ab eo ab eave cui donatum est, ut, si quidem exstet res, vindicetur, si consumpta sit, condicatur hactenus, quatenus locupletior quis eorum factus est" ${ }^{\prime 2}$. De las donaciones que se encuentran prohibidas por el Derecho Civil, de lo que deducimos que entre ellas están las donaciones entre marido (eo) y mujer $(e a)$ se pueden revocar, tanto por el marido o por la mujer (si son o no donantes el uno respecto del otro), lo que conlleva a su invalidez y por tanto tienen según el caso la actio reivindicatio o la actio condictio para pedir su repetición. En el fragmento, Ulpiano expresa que siempre que alguno de ellos se hubiese hecho más rico, la donación se configura y por ende, está prohibida.

D. 24,1,7,3 (31 Sab.): “Aestimari oportere, in quantum locupletior facta sit mulier. Proinde et si praedia hodie vilissimo sunt, consequenter dicemus litis contestatae tempore aestimationem eorum spectandam. Plane si magni pretii praedia sunt, summa tantum numerata erit restituenda, non etiam usurae pretii" ${ }^{33}$. En sintonía con D. 24,1,5,18, la estimación de aquello en lo que cualquiera de los cónyuges se hizo más rico, será determinada según el precio que tenga la cosa donada, o lo que se haya adquirido con la suma de ella, al momento de la contestación de la demanda. Lo planteado nos resulta digno de interés para el efecto económico, al que antes hemos hecho referencia, porque precisamente los precios varían según el mercado, es decir, por diversos factores que se puedan haber presentado en la sociedad romana, que como en toda economía son inciertos, y por tanto, fluctuantes.

${ }^{32}$ Lenel, O., Paling., II, frag. 2.766 (col. 1.140): "Mas en las donaciones prohibidas por el derecho civil de tal modo se revoca lo donado de aquel o de aquella a quien se donó, que si verdaderamente existiera la cosa, se reivindicará, y si hubiera sido consumida, se reclamará por la condictio en tanto cuanto alguno de ellos se hizo más rico".

${ }^{33}$ Lenel, O., Paling., II, frag. 2.766 (col. 1.140): "Y dice el mismo, que también si el marido hubiere donado dinero a la mujer, y esta hubiere comprado con él un predio, debe estimarse en cuanto se haya hecho más rica la mujer. Por lo cual, si los predios son hoy de ínfimo valor, también diremos consiguientemente, que se ha de mirar la estimación de ellos al tiempo de la contestación de la demanda. Pero si los predios son de gran precio, se habrá de restituir solamente la suma entregada, no también los intereses del predio". 
D. 24,1,9,1 (32 Sab.): "Si pecunia accepta mulier manumiserit vel operas ei imposuerit, ait Iulianus operas quidem eam licito iure imposituram et tenere obligationem nec videri mulierem ex re viri locupletiorem fieri, cum eas libertus promittat: quod si pretium ob manumissionem acceperit mulier et sic manumiserit, si quidem ex peculio suo dedit, nummos mariti manere, si vero alius pro eo dedit, fient nummi mulieris: quae sententia recte se habet" ${ }^{34}$. Para comprender mejor este texto, debemos leer previamente D. 24,1,9, pr. (Ulp., 32 Sab.) que antecede al transcrito: "Si eum uxori donet maritus, qui eius erat condicionis, ne umquam ad libertatem perduci possit, dicendum est omnino nibil agi hac donatione" ${ }^{35}$; de lo que se deduce que si la mujer hubiese manumitido un esclavo donado por su marido, sujeto éste a la condición de no poder llegar a la libertad; o bien hubiese prometido sus servicios a un extraño, y en ambos casos hubiese recibido dinero, Ulpiano opina que no se configura la donación entre cónyuges, porque la mujer no se hizo más rica debido a que los dineros son del marido. Nuevamente nos encontramos con el requisito para que estas se constituyan: que uno de los cónyuges se enriquezca como efecto del acto donatorio y agregamos que aun cuando en el texto no se exprese directamente, el marido no se ha hecho más pobre, efecto que depende del anterior.

De los juristas antes expuestos podemos concluir que la exigencia del empobrecimiento del donante y el enriquecimiento del donatario es para las donaciones entre marido y mujer.

\section{La "locupletatio-depauperatio" en las constituciones imperiales.}

Después de haber examinado las fuentes jurisprudenciales pasemos a las constituciones imperiales que mencionan el supuesto elemento locupletatiopauperatio en las donaciones. En general encontramos sólo tres constituciones imperiales que se refieren a la materia, en orden cronológico, la del emperador Gordiano CI. 5,16,9 y otras dos de Diocleciano CI. 5,12,20 y 5, 16,21; cuyo contenido es el que sigue.

CI. 5,16,9 (Gord., a. 238): "Etsi de tua pecunia mancipia uxori tuae com-

${ }^{34}$ Lenel, O., Paling., II, frag. 2.767 (col. 1.141): "Si la mujer lo hubiese manumitido habiendo recibido dinero, o si le hubiere impuesto servicios, dice Juliano, que ciertamente le impondrá con perfecto derecho los servicios, y que es válida la obligación, y que no se considera que la mujer se haga más rica con cosa del marido, prometiéndolos el liberto. Pero si la mujer hubiere recibido precio por la manumisión, y de este modo manumitiere, si aquel verdaderamente los dio de su peculio, los dineros permanecen siendo del marido; pero si otro los dio por él, los dineros se harán de la mujer; cuya opinión es justa”.

35 "Si el marido donase a la mujer uno que era de tal condición, que no podía ser llevado nunca a la libertad, se ha de decir, que no se hace nada absolutamente con esa donación". 
parata sunt, tamen, si ei sunt tradita, eorum dominium non ad te, sed ad eam pertinet, pecuniae autem tantummodo repetitionem habes, sive negotium eius gerens numerationem fecisti sive in eam donationem conferens quantitatem pretii largitus es: etenim vel in solidum vel quatenus locupletior facta est actione cum ea competenti poteris experiri" ${ }^{36}$. Se refiere al caso en que el marido da a su mujer dinero y con éste ella compró unos esclavos. Su efecto es que el dominio ya no le pertenece al primero sino a la mujer y sólo tendrá acción de repetición por la cantidad total o en aquella parte en que se hubiese hecho más rica. Por ende en este caso se configuraría la donación entre cónyuges, ya que su efecto fue el enriquecimiento de la mujer (lo que también implica el resultado del empobrecimiento del marido), por lo que por estar prohibida, es inválida.

CI. 5,12,20 (Diocl., Máx., a. 294): "Pro oneribus matrimonii mariti lucro fructus dotis totius esse, quos ipse cepit, vel, si uxori capere donationis causa permisit, eum in quantum locupletior facta est posse agere manifestissimi iuris $e s t "{ }^{\prime 37}$. Sigue esta línea C. 5, 16, 9, el caso que aquí se señala es aquel en que el marido también tiene acción de repetición contra la mujer en los frutos que la hubiesen hecho ser más rica, es decir, de los que aquél dejó de percibir en favor de ésta, siempre por causa de donación.

CI. 5,16,21 (Diocl. y Máx., a. 294): "Si propriis habitis contractibus quam acceperas mutuam pecuniam pro marito donationis causa erogasti, cum nec ad dignitatem profuerit nec locupletior sit factus, intellegis nullam tibi contra eum competere actionem " ${ }^{\prime 8}$. Todo gasto que la mujer hubiese operado a favor del marido (por causa donandi) y sólo si éste se hubiese hecho más rico, habría acción de repetición en aquello en que el marido se benefició, es decir, en aquello que se enriqueció. Ahora bien, en el caso propuesto por la constitución no acaece tal enriquecimiento, por lo tanto, la mujer no tiene ninguna acción, porque no existe donación.

De la trascripción anterior, podemos observar: $i$ ) que las tres aluden a la

36"Aunque con tu dinero se hayan comprado esclavos para tu mujer, sin embargo, si se le entregaron, su dominio no te pertenece a ti, sino a ella, y tienes solamente la repetición del dinero, ya si hiciste el pago siendo gestor de negocio de ella, ya si haciéndole a ella donación entregaste la cantidad del precio; porque podrás ejercitar contra ella la acción competente, o por la totalidad, o por cuanto se hizo más rica”.

37 "Es de evidentísimo derecho que por razón de las cargas del matrimonio son de lucro del marido los frutos de toda la dote, que el mismo percibió, o que si por causa donación le permitió a la mujer que los percibiera, pueda él ejercitar acción por tanto cuanto se hizo más rica".

38 "Si habiendo celebrado propios contratos, gastaste por causa de donación a favor de tu marido el dinero habías recibido en mutuo, como ni le haya aprovechado para su dignidad, ni se haya hecho más rico, ten entendido que no te compete contra él ninguna acción". 
terminología sólo del enriquecimiento (locupletior) del donatario; ii) todas están en relación con las donaciones entre marido y mujer; iii) la acción de repetición corresponde al cónyuge-donante sólo en la parte en que el otro se hubiese hecho más rico; y iv) finalmente, de lo deducido de las constituciones imperiales, también lo observamos en los pasajes jurisprudenciales expuestos en Pomponio, Terencio Clemente, Papiniano y Ulpiano.

\section{CONCLUSIONES}

De todo el trabajo, podemos ultimar algunas conclusiones que son importantes: En primer lugar, que el Código Civil de Chile exige para que haya una donación entre vivos los requisitos del enriquecimiento del donatario y el empobrecimiento del donante. En comparación con los Códigos civiles estudiados (francés, austríaco, español, alemán y el italiano), podemos afirmar que sale de la órbita de éstos, en cuanto a que ninguno exige el empobrecimiento del donante, y que sólo algunos, como el BGB. y el Código Civil italiano establecen el enriquecimiento del donatario.

En segundo lugar, de acuerdo con el estudio de la romanística consideramos que sólo son las donaciones entre marido y mujer las que exigen como elemento de validez que se produzca el efecto económico del enriquecimiento (locupletatio) en el donatario y el empobrecimiento del donante; así si ellos se producen, aquella donación resulta prohibida, porque se ha configurado entre cónyuges. Por tanto, la locupletatio-depauperatio no son requisitos o elementos exigidos por las donaciones en general. En segundo término, el denominado binomio depauperatio-locupletatio conocido desde Savigny en adelante, y al cual De Robertis atendió con el fin de asimilarlo al concepto de alienatio, afirmamos que no le es aplicable a la donación, pues la disminución patrimonial, efecto que se produce en general en toda donación, no puede ser entendido como una alienatio, debido a que por un lado los juristas en materia propiamente de donación no la aplican (De Robertis en todos los casos la presupone) y cuando estos la utilizan queda restringida a un campo más técnico, que como indica Archi, se refieren a las facultades que compete a un alieni en la administración de su peculio profecticium, a lo que nosotros también adherimos. La noción alienatio tiene más que ver con la facultad de disposición jurídica total que tiene cualquier dueño sobre una cosa, la que se manifiesta en que éste pueda, por ejemplo, venderla o donarla ${ }^{39}$.

\footnotetext{
${ }^{39}$ Cfr., con los siguientes textos de Ulpiano: D. 50,17,165 (Ulp., 53 ed.): “Cum quis possit alienare, poterit et consentire alienationi. Cui autem donare non conceditur, probandum erit nec, si donationis causa consenserit, ratam eius voluntatem habendam" ("Cuando alguno pueda enajenar, podrá también consentir la enajenación. Pero se habrá de admitir, que no se ha de tener por válida la voluntad de aquel a quien no le está
} 
En síntesis, el requisito del enriquecimiento del donatario y el empobrecimiento del donante no son de la esencia de la donatio non mortis causa entre personas extrañas en la donación romana clásica, sino que son exigidos solamente para configurar las donaciones entre marido y mujer.

\section{BiBLIOGRAFÍA}

Abeliuk, René, Derecho sucesorio ( 8 a edición, Santiago de Chile, Editorial Jurídica de Chile, 2012), II.

Albanese, Bernardo, Rec. a Archi, La donazione. Corso di diritto romano [1960], en Scritti Giuridici (Palermo, Palumbo,1991), II.

ArCHI, Gian Gualberto, La donazione. Corso di diritto romano (Milano, Giuffrè, 1960). Archi, Gian Gualberto, La donazione: diritto romano, en Enciclopedia del Diritto (Milano, Giuffrè, 1964), XIII.

BIondi, Biondo, Il concetto di donazioni, en Scritti giuridici (Milano, Giuffrè, 1965), III. Biondi, Biondo, Sucesión testamentaria y donación (trad. cast., Barcelona, Bosch, 1960). D’Ors, Álvaro, Derecho privado romano (9a edición, Pamplona, EUNSA, 1997).

De Robertis, Francesco M., “Alienatio”, en Scritti varii di diritto romano (1939, reimp. Bari, Cacucci 1987), I.

Di Pietro, Alfredo, Derecho privado romano (2a edición, Depalma, Buenos Aires, 1999). Fuenteseca, Pablo, Derecho privado romano (Madrid, E. Sánchez A. Gráficas, 1978). García Garrido, Manuel, Derecho privado romano. Acciones, casos, instituciones (Madrid, Dykinson, 1991).

Giunti, Patricia, Donazione, en Digesto delle discipline privatistiche, Sez. Civile (Torino, UTET, 1991), VII.

Grosso, Giuseppe, Rec. a G.G. Archi, La donazione. Corso di diritto romano (1961), en Scritti storico-giuridici (Torino, Giappichelli, 2001), IV.

Guarino, Antonio, La condanna nei limiti del possibile. Corso di diritto romano (Napoli, 1975).

GuZmán Brito, Alejandro, De las donaciones entre vivos, conceptos y tipos (Santiago de Chile, LexisNexis, 2005).

Guzmán Brito, Alejandro, Derecho privado romano (2a edición, Santiago, Legal Publishing Chile, 2013).

Kiverstein, Abraham, Sucesión por causa de muerte y donaciones entre vivos ( $4^{\mathrm{a}}$ edición, Santiago, La Ley, 2000).

concedido hacer donación, aunque hubiere consentido en la causa de donación"); y D. 50,16,67 (Ulp., 76 ed.): "pr. "Alienatum" non proprie dicitur, quod adhuc in dominio venditoris manet: "venditum" tamen recte dicetur. 1. "Donationis" verbum simpliciter loquendo omnem donationem comprehendisse videtur, sive mortis causa sive non mortis causa fuerit" ("No se dice propiamente "enajenación" lo que todavía permanece en el dominio del vendedor; pero con razón se dirá vendido. 1. La palabra "donación", hablando simplemente, se considera que comprendió toda donación, ya fuere por causa de muerte, ya no por causa de muerte"). 
Lecaros Sánchez, José Miguel, Liberalidades y donaciones irrevocables (Santiago, Metropolitana Ediciones, 1997).

Lenel, Otto, Palingenesia iuris civilis (1889, reimp. Graz, Akad. Druck u. Verlagsanst., 1960).

Luzzatto, Giuseppe Ignazio, Donazione e liberalità. Evoluzione storica di un istituto romano e suoi riflessi sulla dogmatica odierna, en RDPC. 14 (Milano, 1960).

Meza BARros, Ramón, Manual de la sucesión por causa de muerte y donaciones entre vivos ( 8 a edición, Santiago de Chile, Editorial Jurídica de Chile, 2007).

MiQuel, Joan, Curso de derecho romano (Barcelona, PPU, 1987).

SAvignY, F. K., Sistema del derecho romano actual (trad. cast., por Jacinto Mesía y Manuel Poley, Madrid, Editorial de Góngora, 1945), III.

Volterra, Edoardo, Instituzioni di diritto privato romano (1972, trad. Daza como Instituciones de derecho privado romano (Madrid, Civitas, 1986). 